\title{
STRATEGI PENINGKATAN VOLUME PRODUKSI SELADA ROMAINE (LACTUCA SATIVA VAR. LONGIFOLIA) DALAM MEMENUHI PERMINTAAN RITEL MODERN (Studi Kasus di InaGreen Farm, Desa Cikahuripan, Kecamatan Lembang, Kabupaten Bandung Barat, Jawa Barat)
}

\author{
Sakina Intansari Putri ${ }^{1}$ dan Kuswarini Kusno ${ }^{2}$ \\ ${ }^{1,2}$ Program Studi Agribisnis, Fakultas Pertanian, Universitas Padjadjaran
}

\begin{abstract}
ABSTRAK
Dengan kemajuan perekonomian, peningkatan pendapatan, dan kesadaran masyarakat untuk kesehatan dan lingkungan menyebabkan permintaan produk sayuran organik semakin meningkat. InaGreen Farm adalah salah satu perusahaan hortikultura yang bergerak sebagai produsen dan pemasok sayuran organik ke ritel modern Kota Bandung. Perusahaan tersebut menerapkan kegiatan on-farm mulai dari proses pembibitan hingga panen, dan kegiatan off-farm yakni sortasi, pengemasan hingga distribusi. Namun setiap bulannya, InaGreen Farm tidak dapat memenuhi permintaan ritel modern tersebut. Penelitian ini bertujuan untuk mengidentifikasi faktor internal dan eksternal yang menjadi penyebabnya. Jenis data yang digunakan dalam penelitian ini adalah data primer dan sekunder. Data primer diperoleh melalui wawancara lima informan (pemilik, dua kepala divisi, tiga kepala bagian) dan observasi langsung, sedangkan data sekunder diperoleh dari instansi, pustaka, internet, media massa. Analisis data yang digunakan adalah analisis SWOT. Hasil penelitian menunjukkan bahwa kekuatan utama InaGreen Farm adalah pencatatan dan perencanaan usahatani secara teratur; dan kelemahan utamanya adalah atap greenhouse mengalami kerusakan. Sedangkan peluang utama perusahaan adalah pemanfaatan teknologi informasi dan ancaman utamanya adalah hama penyakit yang terus berkembang. Selanjutnya, penelitian ini menghasilkan sembilan alternatif strategi peningkatan volume produksi selada romaine.
\end{abstract}

Kata kunci: selada romaine, manajemen strategi, manajemen produksi

\begin{abstract}
The advancement of the economy, increased revenue, and public awareness for health and the environment led to product demand growing organic vegetables. One of the horticultural enterprises engaged as a manufacturer and supplier of organic vegetables to modern retail Bandung is InaGreen Farm. InaGreen Farm apply on-farm activites of the seedlings to harvest, off-farm activites such as sorting to packaging. However, InaGreen Farm still can't fulfil modern retail's demands. This study aims to identify internal and external factors that influenced the situation. Data was analysed by using SWOT analysis. The results showed that the main strength InaGreen Farm was the recording and planning the farm on a regular basis; and its weakness is the green house roof was damaged. While the main opportunities the company was the use of information technology and its main threats were constantly evolving pests. The result of this research also produced nine alternative strategies for the company in order to improve their condition.
\end{abstract}

Keywords: romaine lettuce, strategy management, prodcution management

\section{PENDAHULUAN}

Menurut IFOAM (International

Federation of Organic Agriculture

Movements) (2005), pertanian organik adalah sistem produksi pertanian yang holistik dan terpadu, mengoptimalkan kesehatan dan produktivitas agroekosistem secara alami sehingga mampu menghasilkan pangan dan serat yang cukup, berkualitas, dan berkelanjutan. Beberapa produk pangan yang dapat dikembangkan dengan sistem pertanian organik di Indonesia adalah tanaman pangan, hortikultura, dan peternakan. Salah satu subsektor hortikultura yang memiliki potensi besar untuk dikembangkan adalah sayuran. Pada tahun 2010 - 2013, produksi komoditas sayuran mengalami peningkatan sebesar 20,4\% (BPS, 2015). Masyarakat 
Indonesia telah memiliki kesadaran terhadap gizi dan kesehatan dengan mengkonsumsi produk sayur-sayuran. Rata-rata pengeluaran per kapita sayur-sayuran cukup tinggi yaitu berada pada posisi ketiga (setelah padi-padian dan ikan) dengan persentase rata-rata peningkatan pengeluaran masyarakat Indonesia yang dialokasikan untuk mengkonsumsi sayur-sayuran sebesar $14 \%$ selama kurun waktu 5 tahun (Gambar 1).

Kecamatan Lembang, Kabupaten Bandung Barat adalah salah satu wilayah yang mampu memproduksi dan menjual sayuran organik ke daerah Jawa Barat maupun luar Jawa Barat. Banyak pelaku usaha sayuran organik daerah Lembang yang telah memasarkan produknya ke pasar domestik maupun ekspor (Sensus Pertanian, 2013).

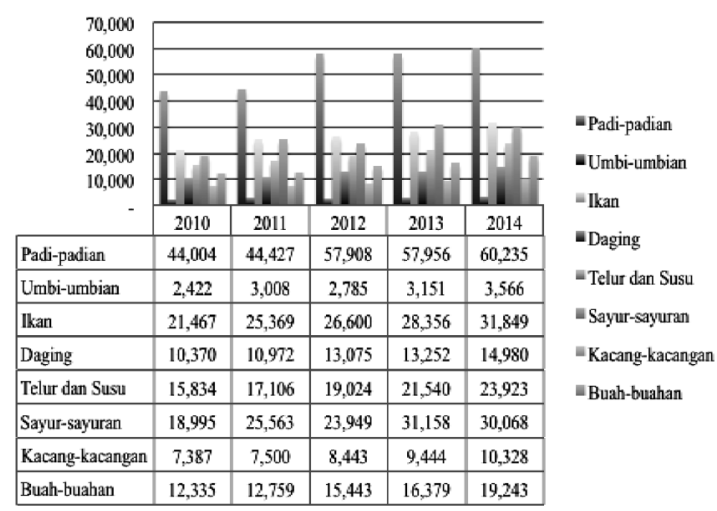

Gambar 1. Rata-rata Pengeluaran per Kapita Sebulan di Daerah Perkotaan dan Perdesaan Indonesia Tahun 2010-2014 (dalam Rupiah)

Salah satu perusahaan hortikultura yang bergerak sebagai pemasok sayuran organik ke ritel-ritel modern di Kota Bandung adalah PT. Indonesia Agroindustri dengan merk produk "InaGreen Farm" yang berlokasi di Desa Cikahuripan, Kecamatan Lembang, Kabupaten Bandung Barat. Perusahaan ini lebih akrab disebut oleh masyarakat sekitar dan para pembeli dengan nama InaGreen Farm. Sayuran organik yang diproduksi berupa sayuran daun diantaranya selada romaine, lollo rossa, endive, selada keriting, pakcoy, caisim, kangkung, bayam merah, bayam hijau, dan horenso.

Selada romaine merupakan komoditas unggulan di InaGreen Farm dan paling banyak diminati konsumen dengan persentase sebesar $14 \%$ dari total permintaan. Namun, rata-rata volume produksi selada romaine setiap bulannya tidak dapat memenuhi permintaan tersebut. Sebesar $21 \%$ rata-rata permintaan selada romaine oleh ritel modern tidak terpenuhi pada periode Februari 2015 Februari 2016. Berdasarkan kendala yang ada, InaGreen Farm harus menjalankan strategi perusahaan yang tepat di kegiatan produksi dan pengadaan produk selada romaine sehingga kendala tersebut dapat teratasi.

Penelitian ini bertujuan mengidentifikasi faktor internal dan eksternal perusahaan dalam meningkatkan produksi selada romaine, merumuskan dan menyusun alternatif strategi di InaGreen Farm.

\section{METODOLOGI PENELITIAN}

Jenis data yang digunakan dalam penelitian ini adalah data primer dan sekunder. Data primer diperoleh melalui wawancara lima informan (pemilik, dua kepala divisi, tiga kepala bagian) dan observasi langsung, sedangkan data sekunder diperoleh dari instansi, pustaka, internet, media massa. Data sekunder digunakan untuk melengkapi data primer.

Penelitian ini dilakukan dengan pendekatan deskriptif. Rancangan analisis data dilakukan dengan beberapa tahap yaitu identifikasi faktor internal dan eksternal oleh Matriks IFAS dan EFAS, penentuan posisi perusahaan saat ini dengan Matriks IE, perumusan strategi alternatif dengan Matriks SWOT.

\section{HASIL DAN PEMBAHASAN}

Analisis Faktor Internal (IFAS).

Analisis faktor internal dan eksternal dilakukan untuk mengetahui kekuatan dan kelemahan utama yang dimiliki oleh perusahaan dalam peningkatan volume produksi selada romaine di InaGreen Farm (Tabel 1). Kekuatan utama dilihat dari skor terbesar dan kelemahan utama dilihat dari skor terkecil.।

Matriks IFAS menunjukkan bahwa kekuatan utama InaGreen Farm adalah pencatatan dan perencanaan usahatani sudah diterapkan secara teratur oleh Kepala Divisi Keuangan dan Administrasi dengan skor ratarata 0.409. Dalam menjalankan usahanya, perencanaan dan pencatatan usahatani merupakan hal penting bagi perusahaan karena memudahkan para kepala divisi untuk menentukan produk yang akan dipanen, mengatur rotasi tanam, mengetahui umur panen yang paling tepat. Oleh karena itu, InaGreen Farm telah menerapkannya sejak perusahaan berdiri. 
Luas lahan produksi InaGreen Farm yaitu 0,7 hektar dengan kondisi atap greenhouse mengalami kerusakan karena kencangnya angin di lokasi kebun. Hal tersebut merupakan kelemahan utama InaGreen Farm dengan skor rata-rata 0.096 karena menyebabkan kualitas menurun dan kontinuitas selada romaine terganggu. Selada romaine merupakan tipe sayuran daun yang tidak dapat mengandung banyak air dan lebih tahan sinar matahari. Busuk batang dan busuk pangkal mudah menyerang tanaman selada romaine saat musim hujan. Kerusakan pada atap greenhouse menimbulkan resiko dari kegiatan budidaya hingga pascapanen.

Setelah diperoleh total skor rata-rata dari faktor internal, maka selanjutnya menentukan kuat-lemahnya faktor internal InaGreen Farm. Nilai total skor rata-rata kekuatan (1.790) lebih besar daripada nilai total skor rata-rata

Tabel 1. Analisis Matriks IFAS

\begin{tabular}{lccc}
\hline Faktor Internal & $\begin{array}{c}\text { Bobot Rata- } \\
\text { rata }\end{array}$ & $\begin{array}{c}\text { Rating Rata- } \\
\text { rata }\end{array}$ & $\begin{array}{c}\text { Skor Rata- } \\
\text { rata }\end{array}$ \\
\hline Kekuatan & & 3.7 & $\mathbf{0 . 4 0 9}$ \\
Pencatatan dan perencanaan usahatani secara teratur & 0.112 & 3.3 & 0.244 \\
Kemudahan menyerap tenaga kerja & 0.073 & 4 & 0.312 \\
Jumlah permintaan produk selada romaine tinggi & 0.078 & 3.3 & 0.280 \\
Input produksi mudah didapatkan & 0.084 & 3 & 0.263 \\
Lokasi perusahaan strategis & 0.088 & 3 & 0.281 \\
Adanya tunjangan perusahaan untuk karyawan & 0.094 & $\mathbf{1 . 7 9 0}$ \\
\hline Jumlah & 0.528 & & 0.103 \\
Kelemahan & & 1 & $\mathbf{0 . 0 9 6}$ \\
Kualitas dan kontinuitas selada romaine belum seragam & 0.103 & 1 & 0.126 \\
Atap green house mengalami kerusakan & 0.096 & 1 & 0.309 \\
Kurangnya relasi dan kerjasama dengan petani/produsen & 0.126 & 2 & 0.114 \\
selada romaine & & 0.155 & $\mathbf{0 . 8 6 2}$ \\
Masih bersertifikasi bebas pestisida & 0.114 & $\mathbf{2 . 6 5 2}$ \\
\hline Lahan untuk produksi terbatas & 0.708 & & \\
\hline Jumlah & & & \\
\hline
\end{tabular}

Tabel 2. Analisis Matriks EFAS

\begin{tabular}{|c|c|c|c|}
\hline Faktor Eksternal & $\begin{array}{c}\text { Bobot Rata- } \\
\text { rata }\end{array}$ & $\begin{array}{c}\text { Rating Rata- } \\
\text { rata }\end{array}$ & $\begin{array}{c}\text { Skor Rata- } \\
\text { rata }\end{array}$ \\
\hline Pemanfaatan teknologi oleh tenaga kerja InaGreen Farm & 0.092 & 3.7 & $\mathbf{0 . 3 3 7}$ \\
\hline Rata-rata masyarakat setempat membudidayakan sayuran & 0.084 & 2.7 & 0.225 \\
\hline $\begin{array}{l}\text { Sudah memiliki pasar yang jelas untuk memasarkan selada } \\
\text { romaine }\end{array}$ & 0.082 & 4 & 0.329 \\
\hline Dukungan pemerintah mengenai Program "Go Organic 2010" & 0.086 & 3 & 0.259 \\
\hline $\begin{array}{l}\text { Perubahan gaya hidup masyarakat yang cenderung back to } \\
\text { nature }\end{array}$ & 0.090 & 3.7 & 0.332 \\
\hline Sistem pembayaran secara retur dan tolak langsung & 0.088 & 3 & 0.265 \\
\hline Jumlah & 0.523 & & 1.746 \\
\hline \multicolumn{4}{|l|}{ Ancaman (Threat) } \\
\hline $\begin{array}{l}\text { Adanya isu bahwa banyak sayuran organik yang beredar di } \\
\text { pasaran tidak } 100 \% \text { organik }\end{array}$ & 0.066 & 2 & 0.133 \\
\hline $\begin{array}{l}\text { Adanya hama dan penyakit yang menyerang pada setiap } \\
\text { musim }\end{array}$ & 0.071 & 1 & 0.071 \\
\hline Sering terjadi gejala alam & 0.080 & 1.3 & 0.107 \\
\hline Kemudahan konsumen mendapatkan produk substitusi & 0.104 & 2.7 & 0.278 \\
\hline $\begin{array}{l}\text { Tidak melakukan kerja sama dengan mitra pengadaan produk } \\
\text { selada romaine }\end{array}$ & 0.075 & 1 & 0.075 \\
\hline $\begin{array}{l}\text { Persediaan selada romaine oleh pemasok (supplier) tidak } \\
\text { menentu }\end{array}$ & 0.080 & 1 & 0.080 \\
\hline Jumlah & 0.471 & & 0.743 \\
\hline Jumlah Total & & & 2.489 \\
\hline
\end{tabular}


kelemahan (0.862), hal ini menunjukkan bahwa InaGreen Farm mampu menggunakan kekuatan untuk menutupi kelemahan yang dimiliki.

Analisis Faktor Eksternal (EFAS). Peluang utama yang dimanfaatkan InaGreen Farm (Tabel 2) adalah pemanfaatan teknologi informasi oleh tenaga kerja InaGreen Farm dengan skor rata-rata 0.337 . Hal tersebut menunjukkan perusahaan merespon tinggi terhadap peluang yaitu dengan memanfaatkan teknologi internet sebagai media pemesanan produk oleh ritel modern. Selain itu, pada kegiatan budidaya juga menggunakan beberapa teknologi berupa hand tractor untuk mengolah lahan, teknologi irigasi dengan sprinkle dan alat packing juga digunakan oleh InaGreen Farm. Ancaman utama yang dihadapi oleh perusahaan adalah hama penyakit yang menyerang pada setiap musim dengan skor rata-rata 0,071 .

Penyakit yang sering menyerang selada romaine adalah busuk batang terutama pada musim hujan. Dengan adanya hama dan penyakit yang terus berkembang menyebabkan kualitas semakin menurun. Hal ini berdampak pada pengembalian produk karena tidak sesuai dengan standar ritel modern.

Setelah diperoleh total skor rata-rata dari faktor eksternal, maka selanjutnya menentukan kuat-tidaknya respon terhadap peluang dan ancaman yang dihadapi InaGreen Farm. Nilai total skor rata-rata peluang (1.746) lebih besar daripada nilai total skor rata-rata ancaman (0.743), hal ini menunjukkan bahwa InaGreen Farm mampu menggunakan peluang yang ada untuk menghadapi ancaman.

\section{Posisi Perusahaan Matiks Internal}

Eksternal (IE). Berdasarkan hasil analisis matriks IFAS dan EFAS, posisi perusahaan terletak pada kuadran $\mathrm{V}$, yaitu mendukung strategi terintegrasi, seperti backward integration, forward integration, dan horizontal integration. Diantara strategistrategi tersebut, strategi yang cocok untuk kondisi riil InaGreen Farm saat ini adalah berbasis strategi integratif ke belakang yaitu menjalin kerjasama dengan mitra ataupun pemasok selada romaine untuk meningkatkan volume produksi. Pemilihan strategi integratif ke belakang karena InaGreen Farm belum memanfaatkan pihak pemasok dan kemitraan untukpengadaan produk selada romaine. Strategi integratif ke belakang diharapkan dapat membantu InaGreen Farm dalam memenuhi permintaan selada romaine. Strategi integratif ke depan dan horizontal tidak dipilih karena tidak sesuai dengan tujuan penelitian.

Strategi Alternatif dengan Analisis

SWOT. Adapun beberapa strategi alternatif yang dapat dirumuskan berdasarkan posisi perusahaan tersebut adalah sebagai berikut: 1) Mempertahankan mutu pelayanan perusahaan kepada pihak ritel modern.

Selain mengutamakan pengiriman produk selada romaine dengan kualitas terbaik, InaGreen Farm juga memperhatikan mutu pelayanan ke ritel-ritel modern. Pelayanan kepada pihak ritel modern antaralain dengan memanfaatkan peluang teknologi dan informasi berupa media internet untuk penerimaan data purchase order, pembayaran tertentu dengan M-Banking sehingga memudahkan kedua pihak. Selain itu, InaGreen Farm memenuhi syarat-syarat kualitas selada romaine yang diinginkan setiap ritel modern. Pelayanan yang diberikan akan mempengaruhi penjualan, terutama pada ritel modern yang menerapkan sistem pembayaran secara retur.

\section{2) Mempertahankan dan meningkatkan pengawasan kegiatan produksi, processing, serta distribusi.}

Dengan adanya pengawasan yang baik oleh kepala divisi produksi dan masing-masing kepala bagian (kebun, processing, dan distribusi) di setiap pekerjaannya diharapkan perusahaan menghasilkan selada romaine yang sesuai dengan keinginan pasar. Pentingnya alternatif strategi ini adalah para kepala bagian dapat mengawasi kinerja anggotanya serta memberi nasihat apabila melakukan kesalahan, sehingga hasil dari setiap kegiatan sesuai dengan yang diharapkan.

3) Menentukan jumlah pemasok tetap selada romaine di luar Desa Cikahuripan.

InaGreen Farm tidak memiliki pemasok tetap selada romaine yang sewaktu-waktu diperlukan akibat rendahnya volume produksi. Hal ini dapat merugikan perusahaan. InaGreen Farm mengandalkan perencanaan usahatani untuk mengetahui jumlah produk yang akan dipanen dan apabila kekurangan produk dalam memenuhi permintaan. Sulitnya pemasok atau petani yang menanam selada romaine organik di sekitar perusahaan mengharuskan kepala divisi produksi menjalin hubungan dan menentukan jumlah pemasok tetap selada 
romaine di luar Desa Cikahuripan agar dapat membantu perusahaan dalam memenuhi permintaan ritel modern. Banyak pemasok tetapi tidak dapat diandalkan akan merugikan perusahaan karena kuantitas maupun kualitas produk tidak terjamin sesuai keinginan perusahaan.

4) Fokus terhadap upaya pengendalian hama penyakit selada romaine.

Upaya pengendalian hama dan penyakit di InaGreen Farm salah satunya dengan melakukan rotasi tanam dengan cara pola tanam Sequential Planning yaitu penanaman dua jenis tanaman atau lebih dalam satu bidang lahan yang dilakukan secara bergiliran. Setelah penanaman selada romaine dilanjutkan dengan menanam komoditas lain seperti pakcoy, caisim, atau kangkung. Hal ini diterapkan untuk mengendalikan hama dan penyakit pada selada romaine yang terus berkembang. Selain rotasi tanaman, pengendalian hama penyakit juga dapat dilakukan dengan cara penyiraman yang teratur, pemupukan yang tepat, dan menjamin kecukupan nutrisi. Jika hama dan penyakit menyerang tanaman cukup parah, pengendalian yang dapat dilakukan yaitu penyemprotan dengan pestisida nabati dan melakukan penyulaman tanaman selada romaine yang terkena penyakit pada umur maksimal 15 hari setelah pindah tanam (Kurniawan, 2010).

5) Rotasi tanam selada romaine di green house harus diperhatikan dan green house segera diperbaiki.

Berdasarkan hasil pengamatan, salah satu kelemahan InaGreen Farm adalah atap greenhouse mengalami kerusakan sejak akhir tahun 2015 yang disebabkan oleh angin di lokasi kebun. Tingginya permintaan selada romaine dibandingkan komoditas lainnya, diharapkan InaGreen Farm menanam selada romaine di dalam greenhouse terutama pada musim hujan. Karakteristik selada romaine yaitu tidak tahan terlalu banyak air karena mudah mengalami busuk batang sehingga tampilan selada romaine saat musim hujan dan kemarau pun sangat berbeda. Pada musim hujan, rata-rata hasil selada romaine yang ditanam di dalam greenhouse lebih baik dibanding di luar greenhouse, oleh karena itu rotasi tanam selada romaine di dalam greenhouse harus lebih diutamakan dibandingkan komoditas lainnya.
6) Standarisasi kualitas selada romaine saat kegiatan processing oleh karyawan harus seragam.

Standarisasi kualitas selada romaine dalam kegiatan sortasi merupakan hal yang perlu diperhatikan. Jika terjadi perbedaan antar karyawan processing satu sama lain, maka akan mempengaruhi volume produksi. Tahap sortasi yang tidak sesuai dengan standar yang jelas juga akan berdampak pada rendahnya volume produksi. Berdasarkan hasil pengamatan, masih ada karyawan processing yang tidak mengetahui mana daun selada romaine yang sebaiknya dibuang dan mana yang masih layak. Standarisasi kualitas sebaiknya disesuaikan dengan musim, akibat dari greenhouse yang mengalami kerusakan dan belum diperbaiki menyebabkan para karyawan di bagian produksi maupun processing harus ekstra teliti dalam memelihara tanaman selada romaine. 7) Penambahan area produksi.

Kurangnya lahan untuk produksi di InaGreen Farm menjadi salah satu penyebab rendahnya volume produksi selada romaine. Kondisi alam Kecamatan Lembang sesuai dengan syarat tumbuh selada romaine (Sastradihardja, 2011). Penambahan area produksi dapat dilakukan salah satunya dengan membeli atau menyewa lahan pertanian di daerah sekitar Lembang. Dengan kondisi ratarata masyarakat setempat membudidayakan sayuran dan pihak perusahaan sedang menjalin hubungan kerjasama dengan masyarakat sekitar akan lebih memudahkan perusahaan mendapatkan lahan pertanian untuk menambah area produksi.

\section{8) Menjalin kerjasama dengan petani mitra selada romaine.}

InaGreen Farm hanya menjalin

kerjasama dengan mitra pembibitan oleh Ibu Euis yang berlokasi tidak jauh dari perusahaan. Tidak ada bentuk kerjasama untuk pengadaan produk selada romaine karena dianggap tidak dapat menguntungkan perusahaan dan takut kesepakatan dilanggar oleh salah satu pihak. Lokasi petani mitra yang akan diajak kerjasama yaitu petani yang berada di daerah Lembang karena tidak jauh dari lokasi perusahaan dan pengawasan akan lebih mudah. Tujuan menjalin kerjasama oleh petani mitra yaitu membantu perusahaan untuk memenuhi permintaan ritel modern apabila produksi perusahaan di kebun milik sendiri rendah. 


\section{9) Mengusahakan label sertifikat organik Indonesia melalui lembaga resmi sertifikasi organik.}

Alternatif strategi ini dibuat untuk memperbaiki kelemahan perusahaan yaitu masih bersertifikasi bebas pestisida. Dengan adanya isu bahwa sayuran organik yang beredar di pasaran tidak $100 \%$ organik menjadi suatu ancaman bagi perusahaan karena produk InaGreen Farm belum bersertifikasi organik dan pada kemasan produk InaGreen Farm juga belum terdapat label Organik Indonesia dari lembaga sertifikasi organik.

\section{KESIMPULAN}

Faktor yang menjadi kekuatan utama InaGreen Farm adalah sudah menerapkan pencatatan dan perencanaan usahatani secara teratur. Sedangkan kelemahan utama perusahaan adalah atap greenhouse mengalami kerusakan. Faktor yang menjadi peluang utama bagi InaGreen Farm adalah perkembangan teknologi informasi. Ancaman utama yang harus dihadapi perusahaan adalah hama penyakit yang menyerang pada setiap musim.

Hasil analisis SWOT menghasilkan sembilan alternatif strategi yang dapat dijalankan oleh InaGreen Farm yaitu: 1) Mempertahankan kualitas dan mutu pelayanan perusahaan kepada pihak ritel modern; 2) Mempertahankan dan meningkatkan pengawasan kegiatan produksi, processing, dan distribusi; 3) Menentukan jumlah pemasok tetap selada romaine; 4) Fokus terhadap upaya pengendalian hama penyakit selada romaine; 5) Rotasi tanam selada romaine di greenhouse harus diperhatikan dan greenhouse segera diperbaiki; 6) Standarisasi kualitas selada romaine saat kegiatan processing oleh karyawan harus seragam; 7) Menambah area produksi; 8) Menjalin kerjasama kemitraan produk selada romaine; 9) Mengusahakan sertifikat organik Indonesia melalui lembaga resmi sertifikasi organik.

InaGreen Farm sebaiknya membuat SOP secara terpampang, sehingga karyawan secara seragam dapat mengetahui dan paham prosedur dalam proses sortasi. Jika hama dan penyakit sudah parah sebaiknya menggunakan pestisida nabati yang dijual di toko-toko pertanian dan dilakukan penyulaman tanaman segera mungkin untuk tanaman yang terkena penyakit.

Kegiatan promosi harus tetap dilakukan dengan mengikutsertakan produk InaGreen Farm ke dalam bazar-bazar pertanian organik agar produk InaGreen Farm lebih dikenal oleh masyarakat luas. Pemerintah diharapkan untuk berpihak pada pelaku usaha pertanian organik terutama sub-sektor hortikulutra dengan membuat sebuah program seperti program pengembangan teknologi pertanian berkelanjutan melalui peningkatan aplikasi pertanian organik.

\section{UCAPAN TERIMAKASIH}

Terimakasih kepada semua pihak yang telah membantu dalam penyelesaian jurnal ini.

\section{DAFTAR PUSTAKA}

Agus G.T.K et al, 2002. Menanam Sayuran di Perkarangan Rumah. Jakarta: Agromedia Pustaka.

Assauri, Sofjan. 2004. Manajemen Produksi dan Operasi Edisi Revisi 2004. Jakarta: Lembaga Penerbit FE-UI.

Badan Ketahanan Pangan. 2015. Perkembangan Produksi Komoditas Sayuran Indonesia. Kementrian Pertanian RI.

Badan Meteorologi, Klimatologi, dan Geofisika. 2010. http://data.bmkg.go.id.

Badan Pusat Statistik. 2014. Hasil Sensus Pertanian 2013 Kabupaten Jawa Barat. http://bps.go.id.

David, Fred R. 2006. Manajemen Strategis Konsep. Prentice Hall Inc. New Jersey.

Department of Agriculture.2005. Australian and International Organic Certifier. http://nasaa.com.au.

Direktorat Jenderal Hortikultura. 2008. Pengembangan Sayuran Organik di Jawa Barat. Kementrian Pertanian RI.

Ekojono dan Parastiwi, Andriani. 2011. Perancangan Sistem Pendukung Pengambilan Keputusan Penentuan Jenis Sayuran Organik Berdasar Parameter Fisik dan Kimia. Jurnal ELTEK, Vol 09, No. 02. Malang: Politeknik Negeri Malang.

IFOAM. 2005. The IFOAM Norms of Organic Production and Processing. Germany: IFOAM. http://ifoam.org.

Kotler, P. and K.L. Keller (2012). Marketing Management, $14^{\text {th }}$ ed. Upper Saddle Rive. NJ: Pearson Education.

Kurniawan, Firman. 2010. Mengenal Tanah Sebagai Media Tanam. Bogor: Bogor Agricultural University.

Ommani, Ahmad Reza. 2011. SWOT Analysis for Farming System Business Management: 
Case of Wheat Farmers of Shadervan District, Shoustar Township, Iran. African Journal of Business Management Vol 5 No. 22. Iran: Islamic Azad University. Rangkuti, Freddy. 2105. Teknik Membedah Kasus Bisnis: Analisis SWOT. Edisi 21. Jakarta: PT. Gramedia Pustaka Utama.

Sastradihardja, S. 2011. Praktis Bertanam Selada \& Andewi Secara Organik. Bandung: Angkasa.

Sholehana, Amalia, Rizal Syarief, dan Agus Maulana. 2012. Formulasi Strategi Peningkatan Produksi Domba CV Mitra Tani Farm, Ciampea, Bogor. Jurnal
Manajemen\&Agribisnis, Vol. 9 No 2. Bogor: Institut Pertanian Bogor.

Splittstoesser, W. E. 1990.Vegetable Growing Handbook: Organic and Traditional Methods, $3^{\text {rd }}$ ed. New York: Van Nostrand Reinhold.

Sugiyono. 2012. Metode penelitian Kuantitatif dan Kualitatif. Bandung: Alfabeta.

Sutarminingsih, L. 2007. Vertikultur. Yogyakarta: Kanisius.

Wheelen, Thomas dan J. David Hunger. 2012. Strategic Management and Business Policy: Toward Global Sustainability $13^{\text {th }}$ ed. New Jersey: Pearson Education Inc 